\title{
The Rule of Law and Technocratisation
}

\section{Christopher May ${ }^{1}$}

Published online: 5 November 2019

(C) The Author(s) 2019

\section{Introduction}

In the Twentieth century, the rule of law became, in many ways, the common sense of global politics. It managed to be both a norm, in that it was treated as an aspiration for political organisation, and it was seen as a technique of good governance, to be deployed as a corrective to the variety of political gaps (or 'lacks') that international institutions identified in various cases of state failure. More recently, it has become possible to argue that we may have passed 'peak rule of law' as countries and leaders seem in their actions and in their rhetoric, to be resistant to the political or social value of the rule of law. This (partial) dismissal of the rule of law may be related to the issue of the pervasive technocratisation of rule of law 'assistance'; the deployment of the rule of law qua technology can be a major impediment to establishing the very rule of law that would produce the effects such programmes intend.

The rule of law has been the subject (as is conventionally acknowledged) to considerable debate as regards its character and core/necessary elements. Scholars and commentators have mostly regarded the rule of law as being either thin (procedural) or thick (carrying with it a range of normative requirements). This can be presented as a pair of alternatives, or more usefully, as a continuum between two extreme nodal points along which various understandings of the rule of law might be arrayed or placed (May 2014, chapter two). While many (or even most) analysts in developed states would agree that the rule of law might be the preferred mode of governance, there is little agreement on what that means in practical political terms. This led Martin Krygier to conclude:

In societies where the rule of law has long been secure, the fact that it is misconceived might not matter too much, since to a considerable extent it runs on its own steam. However in conflictual, post-conflict and transitional societies, where efforts are made to catalyse the rule of law these problems can be catastrophic (Krygier 2011, p. 32).

Christopher May

c.may@lancaster.ac.uk

1 Political Economy, Lancaster University, Lancaster, UK 
This is to say, what might be academic questions for lawyers in states with stable and well-embedded legal systems, can lead to significant problems when the rule of law is being 'introduced' to a political system where it is perceived as having been absent (or incomplete), or is being used as a benchmark to 'measure' a specific system of governance for legitimacy or acceptability. Moreover, Krygier is dismayed at depictions of the rule of law as a form a technology (especially common among those who adopt a relatively thin definition) that can be applied with little account of the social milieu into which it is to be introduced (Krygier 2006, p. 157). When the rule of law is treated as undifferentiated and settled technology to be deployed as a 'transplant' much of its flexibility is lost or wilfully ignored, leading to problems in its reception as an acceptable aspiration for governance practice(s).

So, the cultural or normative element of the rule of law, which allows it both flexibility in interpretation but also to enjoy the status of common sense is undermined when a more monolithic technology-like version is presented as a developmental strategy for failing or failed states. To be clear, however, Krygier also warns that we should not reify 'culture' into a catch all residual category where any impediments to introducing the rule of law can be located and thus blame shifted to the recipients of technical assistance (Krygier 2011, p. 31). The failure of the rule of law to attain acceptance as a common-sense of governance in any particular incidence is not the failure to correctly engineer an interface between the rule of law and society, but may rather reveal the partiality of the rule of law qua technology strategy in the first place. It is the contours of this failure that I want to briefly examine here.

\section{The Temptation and Danger of Technocratisation}

The idea of technocratisation is an often utilised term, even if there seems to be little shared definition across the disciplinary fields in which it is deployed. While in general it refers to the idea of social issues/factors being rendered as neutral mechanisms, here I'll rely on Robin Stryker's definition of the technocratisation of law. It is, he argues:

The movement toward exclusive use of causal reasoning by scientific- technical experts to make and administer state policy. Law in any area can provide a framework of rules to be interpreted, applied, or even created by scientifictechnical experts establishing and applying general cause-effect relations, rather than by lawyers using legal reasoning (Stryker 1989, p. 342).

Moreover, this is intended by the agency involved to depoliticise the intervention. Indeed, for the World Bank specifically (due to its constitution), and implicitly for other agencies, any rule of law based intervention needs to be rendered as scientific/ technical and not political for it to be seen as a legitimate activity in the first place (May 2014, p. xxxi-xxxvii). Thus, rather than a political intervention, which might be seen to be problematic both by the institution and the 'recipient' state, the rendering of the rule of law as technology that merely needs to be implemented serves a range of political interests. 
The technocratisation of the rule of law reflects the interest of institutions in having a standardised set of procedures which can be used for tendering $\&$ assessment purposes. It allows for clearly delimited and specified tenders, and for relatively easy to measure metrics of implementation success; for instance numbers of individuals trained in law-related practice(s) or the increase in number of judges sitting in regional courts. Therefore, in this technical approach, contractors have clear outputs to deliver and these are supported by standardised practices and materials. Perhaps most importantly, rather than have well-trained professional lawyers for whom the law is not a monolithic 'rule book' but rather a series of contested discussions and decisions, the implementation of rule of law assistance has fallen largely to what at best might be (and often are) referred to as para-legals. This is to say, technicians who have been, perhaps incompletely, inculcated into the idea of the rule of law as a norm socially but lack the legal experience to recognise the contingency that practicing lawyers deal with on a daily basis. One might say that they are untroubled by knowledge of the complexities of the law, seeing it only as a formal system of rules, procedures and agencies which need introducing where they are lacking.

Although for many academic analysts the rule of law is an issue of the expansion of more democratic forms of governance (and government), for the World Bank especially (but also other funders) much of the focus on the rule of law is due to the perception that it underpins preferred forms of economic development. This view places the rule of law into a specific relationship with society and economic development; it mandates a clear prioritisation of property rights, contract law and market enhancing regulatory forms, and under-emphasises the introduction of other social and/or political aspects of the norm of the rule of law especially relevant to its 'thicker' version. This most often plays out in the discussion of sequencing of reform, with aspects that are professed to support economic development being prioritised and other more political elements being delayed and/or downplayed. The technocratic version of the rule of law is concerned only with those cause/effect relations' in which the range of effects that are regarded as key to implementation being regarded a 'success' are constrained and limited in scope to the economic.

This thinner notion of the rule of law can be a dangerous temptation. The rule of law is often 'sold' to social actors on the basis of its wider range of benefits (related to the Westernised norms of the thicker norm) such as helping support social justice and the reduction of inequality; social support for programmes is sought on the basis of the positive social impact(s). However, if the delivery of the rule of law becomes (for sequencing, or political reasons) merely the implementation of economic sector legal structures intended to facilitate the expansion of market relations, then for those outside business elites, the introduction of the rule of law may be perceived as the de-legitimisation of traditional and customary forms of local (economic) governance with no concomitant improvement in the legal regime around human rights or other aspects of the claimed social value of the rule of law.

Alongside the focus only on issues of market institutionalisation and economic effects, another key danger of the technocratic view of the rule of law, perhaps unsurprisingly, is that it fails to accord sufficient weight to the local mores and forms of governance in the 'recipient' society; all forms of legality that do not match the new legal technology are rendered as problems to be surmounted. This ignores and/ 
or downplays the real history of the development of the rule of law and its actuality in the states regarded as emblematic of its pinnacle of existence; it denies the contingent and organic development of what we now call the rule of law. In developed countries the rule of law had a long and difficult gestation, often contested and certainly contingent on local/national politics at various historical moments. However, this de-historisation is not perhaps so surprising given the expressed link between law and economic development; economics has its own problem with historical myopia (Hodgson 2001), and when law is seen as a technology to be deployed to produce economic effects in another mechanism regarded also (wrongly) as a desocialised mechanism, the market, it is effectively wrenched out of any history it might be related to. This view supplants a more pluralist idea of the rule of law that would focus on the negotiation between legal formalism and cultural practice, that would be sensitive to established (and thereby legitimated) governance norms and would therefore require significantly more expert knowledge of other systems of law to explore forms of settlement that would allow the forms of social value attributed to the thicker rule of law norm to begin to be actuated.

The technical approach to introducing the rule of law to societies whose own (customary) legal system is not seen as 'law' to the supporters of standardised forms of economic governance is a form of bait and switch. The promise is for the promotion of the forms of rights that (through global communications) are now often wellknown to local populations, while the implementation of the rule of law focusses on the integration of the economy into a globalised economic system in which such rights are less integral. This may lead to the diminution of the rule of law and the relative decline as a powerful norm of global politics. On one level this is clearly a negative development: the utilisation of the technical approach to the rule of law allows a form of legality shorn of any real interest in anything other than the interests of a specific subset of socio-economic actors; the global construction of a legal constitution for the protection and accumulation of capital (Cutler 2018). Conversely, it is also possible to frame these developments in a more positive way: elsewhere I have concluded that for the rule of law to continue as a global common sense one has to recognise is normative variability or plurality, while also hoping that familiarity with the 'logic' of the rule of law would move states and societies slowly along the continuum of thin to thick understandings of the norm (May 2014, pp. 186-187) and it is this more positive framing with which I conclude.

\section{The Rule of Law: Starting at the Beginning}

Certainly, much can be made of the negative developments that I outline above, and indeed much critical commentary focusses on the gap between the promise and the actuality of the rule of law as implemented in various types of technical assistance and/or capacity building programmes. Here the rule of law, in its thicker form, is betrayed by a 'neoliberal' concern to facilitate markets and ensure the key economic actors' interests are privileged, often through an argument that their success will 'trickle down' to society more widely. There is much to this criticism that I would not dismiss nor wish to argue against. However, there is also, perhaps a more 
positive way of seeing the contemporary situation of the rule of law, which implicitly appeals to its long and gradual history of development in those states that we might easily regard as enjoying a thicker rule of law.

If we do not wrench the rule of law out of history, we can see its current settlement in European and Western states not as refined and perfected technology, but rather as a contingent (and currently legitimated) contemporary settlement in a long contentious history. This then suggests that countries and societies that have partial, ineffective or unreliable legal systems are needing not to have a monolithic (globalised, liberal) thick rule of law norm installed (displacing local legality), but rather need to navigate their own political history to a form of the rule of law that best reflects their social mores and history. Certainly there may be some irreducible elements that are required for the rule of law to be said to obtain; the thinner norm can be heavily reduced, and at its thinnest might only require that the key value of predictability be respected (May 2018). This then means that the technocratic implantation of economically-focussed legal structures already moves any countries' rule of law off the baseline of the thinnest possible conception of the norm. The question then is: can societies navigate their historical trajectory towards a thicker rule of law without aid and support from outside?

On one side is the interventionist argument that they cannot, but this approach has been fatally undermined by the bait and switch of technical assistance. On the other, if we take legal history seriously then the rule of law, albeit often informed by legal transplants (from imperial powers or via technical assistance) relies in the last analysis on the rights that a society is willing to establish for itself via political action and mobilisation. In the face of leaders in global public forums seeming to dispute the value of the norm of the rule of law, or through their actions giving the lie to any proclamations they may make about being constrained by the rule of law, this might suggest a programme of emancipatory local politics would actually best reflect the real developmental history of the rule of law.

So, if technical assistance can only go so far, what is the alternative if those interested in the rule of law are not to be advised that no intervention will produce the forms of robust rule of law that internal political struggle may finally establish? In global trade relations the Quaker Office for the United Nations has done a lot of quiet working behind the scenes building expertise and capacity for developing countries to work in negotiations at the World Trade Organisation, with a slow but very positive impact of allowing these countries to utilise the organisation in ways that at its initiation were thought to be only available to the large richer members. A similar programme, building on the work of educators and organisations to help social actors, community leaders and states' legislators develop their political capacity to push forward when rule of law developmental opportunities arise might be a better fit with the real history of the rule of law. I am not arguing that this is not happening already, but rather that it needs to be better foregrounded in our understanding of how to (eventually) establish a global rule of law.

Certainly, such programmes have little immediate impact on authoritarian states, but equally this form of emancipatory politics, producing cohorts of people who are ready to seize political opportunities to move their country along the rule of law continuum may be the most realistic hope for a real global rule of law. This suggests 
it may be best to focus on societies that are aspiring to thickening the rule of law and perhaps already have forms of legality well-grounded in their institutions. This may have few immediately measurable outcomes and require a faith in the positive possibilities of the rule of law, but at least can plausible support the social, cultural and political negotiations that are the key to the long term development of rule of law states. We have tried extensive technical assistance in the economic sphere, now might be the time to focus on something different.

Open Access This article is distributed under the terms of the Creative Commons Attribution 4.0 International License (http://creativecommons.org/licenses/by/4.0/), which permits unrestricted use, distribution, and reproduction in any medium, provided you give appropriate credit to the original author(s) and the source, provide a link to the Creative Commons license, and indicate if changes were made.

\section{References}

Cutler AC (2018) The rule of law, new constitutionalism, and transnational legality. In: May C, Winchester A (eds) Handbook on the rule of law. Edward Elgar Publishing, Cheltenham

Hodgson GM (2001) How economics forgot history: the problem of historical specificity in social science. Routledge, Abingdon

Krygier M (2006) The rule of law: an Abuser's guide. In: Sajó A (ed) Abuse: the dark side of fundamental rights. Eleven International Publishing, Utrecht

Krygier M (2011) Approaching the rule of law. In: Mason W (ed) The rule of law in Afghanistan: missing in action. Cambridge University Press, Cambridge

May C (2014) The rule of law: the common sense of global politics. Edward Elgar Publishing, Cheltenham

May C (2018) The centrality of predictability to the rule of law. In: May C, Winchester A (eds) Handbook on the rule of law. Edward Elgar Publishing, Cheltenham

Stryker R (1989) Limits on technocratization of the law: the elimination of the national labor relations board's division of economic research. Am Sociol Rev 54(3):341-358

Publisher's Note Springer Nature remains neutral with regard to jurisdictional claims in published maps and institutional affiliations. 